Article

\title{
Regional Economic Resilience of the Old Industrial Bases in China-A Case Study of Liaoning Province
}

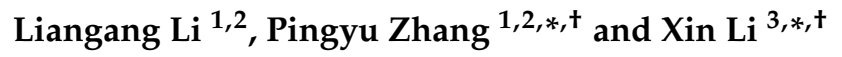 \\ 1 Northeast Institute of Geography and Agroecology, Chinese Academy of Sciences, Changchun 130002, \\ China; liliangang@iga.ac.cn \\ 2 College of Resources and Environment, University of Chinese Academy of Sciences, Beijing 100049, China \\ 3 College of Public Administration, Nanjing Agricultural University, Nanjing 210095, China \\ * Correspondence: zhangpy@neigae.ac.cn (P.Z.); xinli@njau.edu.cn (X.L.); \\ Tel.: +86-431-85542275 (P.Z.); +86-025-84395700 (X.L.); Fax: +86-431-85542206 (P.Z.) \\ + P.Z. is the first correspondence author and X.L. is the second correspondence author.
}

Received: 12 January 2019; Accepted: 28 January 2019; Published: 30 January 2019

\begin{abstract}
Regional economic resilience provides a new perspective for explaining regional differences in response to recession shocks. This paper analyzed the regional economic resilience of Liaoning Province in China in terms of its resistance and recoverability dimensions from 1990 to 2015 and explored the determinants of regional economic resilience by constructing a spatial econometric model using panel data. There are three main findings. First, the level of regional economic resilience in Liaoning was low and its urban economy was more vulnerable to external shocks than that of the whole nation. Second, we found that factors such as the local governance arrangement, the regional innovation ability, and the level of economic diversification have significant positive effects on regional economic resilience. Factors such as the proportion of secondary industry and the GDP negatively affect regional economic resilience. Third, regional economic resilience demonstrates a spatial autocorrelation, and the improvement of economic resilience in the surrounding areas will lead to the decline of regional economic resilience.
\end{abstract}

Keywords: regional economic resilience; influence factors; spatial econometric; old industrial bases in China; Liaoning Province

\section{Introduction}

Regional economic development is a dynamic process that is often affected by financial crisis, recession and other shocks [1,2]. It is often found that some regions can actively respond to external shocks and achieve sustainable economic development, while others are seriously affected by shocks and enter the long-lasting recession trajectory $[1,3]$. These differences in the ability to deal with shocks have led to different development states among regions. Investigating how and why different regions respond differently to the shocks has attracted much academic attention to economic geography and regional studies $[1,3,4]$. In particular, many policy makers and studies are eager to know how old industrial bases respond to shocks and further realize economic revitalization. This is because old industrial bases are more vulnerable to shocks, such as financial crisis and resource depletion [3,5-7], and to falling into the trajectory of economic recession due to their special regional characteristics. Therefore, old industrial bases have an urgent need to improve their ability to cope with shocks and maintain long-term development of the regional economy.

Resilience has been a significant term for exploring the mechanisms and displaying the dynamics of how a system, or an individual, responds to and recovers from a shock [3,8-11]. The notion of resilience was first developed in engineering and ecological sciences $[6,11,12]$ and was used to 
explain the ability of systems to return to their equilibrium states when subjected to shocks $[3,11]$. When locating resilience in an evolutionary framework, it means the capacity of a region to sustain long-term development while experiencing change, adaptation and transformation to recovery after a shock [3,4]. In the regional economic research basin, evolutionary resilience is also named regional economic resilience [2,11]. Regional economic resilience, as explained by Martin and Sunley, means the capacity of a regional economy to withstand or recover from market, competitive, and environmental shocks to its previous developmental path, or transition to a new sustainable path [11]. Since the 1980s, the global economy has experienced several rounds of recessions, which have had significant influences on the development of regional economy [1-3,13,14]. Regional economic resilience has become a popular notion and is used by economic geographers and regional economists to explain why regional economies respond differently to shocks $[11,15,16]$. The current research mainly focuses on the study of the definition of regional economic resilience $[1,11,17,18]$. Additionally, there are many qualitative or quantitative empirical studies $[8,19,20]$ that use GDP growth rate, GDP, employment rate, and other indicators to analyze regional economic resilience in Western countries such as Europe, the USA, the UK, and Italy [2,8,21-23]. However, research on regional economic resilience in China is still limited. There are still many shortcomings in the existing research. First, most of the existing research has selected the influencing factors of regional economic resilience to be within a single time period from certain types of factors such as industrial structure [24,25], technological innovation ability $[23,25]$, financial environment $[11,26]$, and labor force [6,27]. However, the dimensions of the influencing factors are not comprehensive enough, and the factors related to government arrangements have been ignored $[19,28]$. Second, there is a lack of research on the determinants of regional economic resilience in multiple consecutive time periods by building panel data models. Third, the existing studies mainly focus on a national scale rather than regional scales, and spatial homogeneity is often assumed as a precondition in most studies, which is very likely to cause the regional characteristics [6] and the spatial correlations of different spatial unit properties to be ignored.

Driven by the above concerns, this paper studies the regional economic resilience of China, taking the Liaoning old industrial base as a case study. The paper also explores its determinants from 1990 to 2015 by establishing a panel data spatial econometric model. Liaoning Province is one of China's most important old industrial bases. The regional economic development is dominated by heavy industry, and there are still many resources and labor-intensive industries present there, which have contributed to the initial development of New China [29,30]. After China's reform and opening up, Liaoning Province could not fully adapt to the market economy, and in the 1990s, there were a large number of enterprises that collapsed, leaving many workers unemployed in Liaoning. At the same time, affected by the Asian financial crisis, Liaoning's economy had further declined and experienced a great recession. Implementing the strategy of revitalizing old industrial bases in Northeast China in 2003 was intended to prompt the recovery of the local economy. However, the international financial crisis in 2008 had a negative impact on its economy. In 2014, the economic "cliff-like drop" in Northeast China occurred [31], and Liaoning's economic development slowed down. Therefore, Liaoning, as the core province of the old industrial bases in Northeast China, has a typical fluctuation of economic developments, and is more vulnerable to shocks. It is a typical case that can be combined with regional economic resilience to reveal how the old industrial bases react to domestic economic reforms and external disturbances, and what factors are influential to the region's reaction to shocks are the central focuses of our research.

The remainder of the paper proceeds as follows: Section 2 describes the study area; Section 3 measures the regional economic resilience; Section 4 analyzes the determinants of regional economic resilience; and Section 5 discusses the main findings and summarizes the conclusions.

\section{Study Area and Major Recessionary Shocks}

Liaoning Province is a traditional old industrial base in China. It has 14 prefecture-level cities (Figure 1), which are all old industrial cities. Liaoning Province has developed a relatively complete 
industrial system since the establishment of the People's Republic of China (PRC) in 1949. Due to its outstanding contributions to the national industrial economy, it was called the cradle and the eldest son of the PRC [32]. In later sections, we will explain the industrial development history of Liaoning Province.

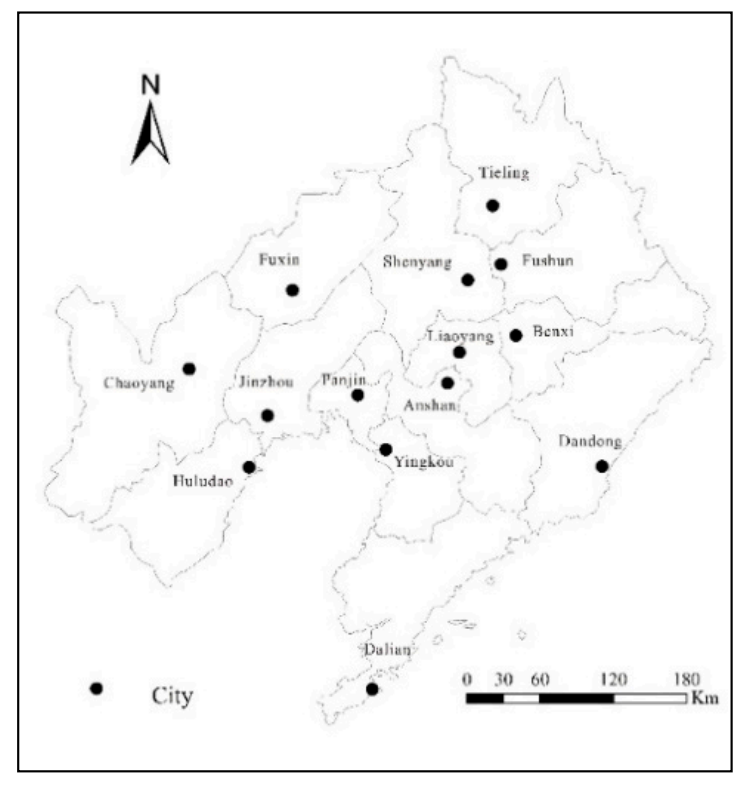

Figure 1. Spatial distribution of cities in Liaoning Province.

The economic development of Liaoning Province has experienced its ups and downs since the establishment of the PRC. During the period of the First Five-Year Plan (1953-1957), about one-sixth of the state's modern industrial system construction projects were located in Liaoning [30]. By 1957, Liaoning's heavy industry output value was ranked the highest in China [32]. In the early 1990s, economic development was slowing in Northeast China; however, the economy in other parts of China developed rapidly, and the economic growth rate of Liaoning Province significantly declined. The "Revitalization of Old Industrial Bases in Northeast China" strategy was implemented in 2003, and the heavy chemical industry in Liaoning Province recovered and developed [30]. Influenced by the 2008 financial crisis, the GDP growth rate of Liaoning has dropped to 3\% in 2015, which is the lowest in comparison with the other provinces of China.

The economic development of Liaoning relies on traditional industries such as mining industries. The industrial structure of Liaoning Province has been dominated by secondary industry $[29,30]$. For instance, the proportions of its secondary industry in 1992, 1999, 2007, and 2015 were 50\%, 48\%, $50 \%$, and $46 \%$, respectively. At the same time, the secondary industry of Liaoning is dominated by heavy industry $[30,32,33]$, and the heavy industry's GDP has accounted for more than $70 \%$ of the total secondary industry for a long time. Liaoning is severely restricted by natural resources and the international market. In addition, Liaoning has multiple resource-based cities and the proportion of state-owned enterprises is large [30], which in turn has led to a rigid and single industrial structure in Liaoning. This industrial structure is vulnerable to shocks [29].

This paper divides the regional economic cycle by the change of GDP growth rate [6,7]. Figures 2 and 3 show the GDP growth rates in China and the 14 prefecture-level cities in Liaoning, respectively, since 1990. From Figures 2 and 3, we can see that the trend of urban economic growth rate in Liaoning was similar to that of the whole country. To make these data comparable between cities, the paper uses the "peak-to-peak" method (measuring from one peak to another peak for one economic cycle) to divide the economic cycle with reference to the change of GDP growth rate at the national level $[7,8]$. As shown in Figure 2, from 1992 to 1999, the national GDP growth rate declined from 14.3\% to 7.6\%, 
which was mainly due to the retrenchment of China's market economic reform and the Asian financial crisis. This stage was in the contraction period of economic growth. From 1999 to 2007, the national GDP growth rate increased from $7.6 \%$ to $14.2 \%$. This stage was in the expansion period of economic growth. From 2007 to 2015, the national GDP growth rate decreased from $14.2 \%$ to $6.9 \%$, which was mainly due to the global financial crisis occurring since 2008. This stage was in the contraction period of economic growth. As shown in Figure 3, there were significant differences in how different cities in Liaoning respond to shocks. Some cities such as Dalian were less affected by shocks, and their economy recovered more quickly than other cities which were more vulnerable, such as Chaoyang.

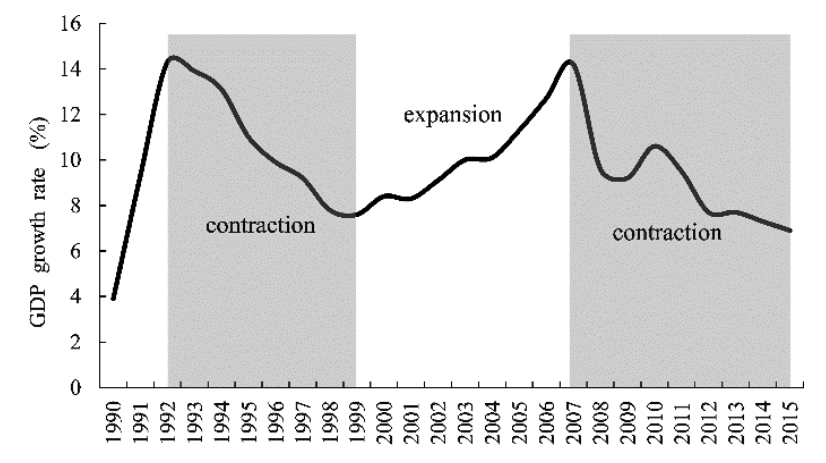

Figure 2. GDP growth rates in China (1990-2015).
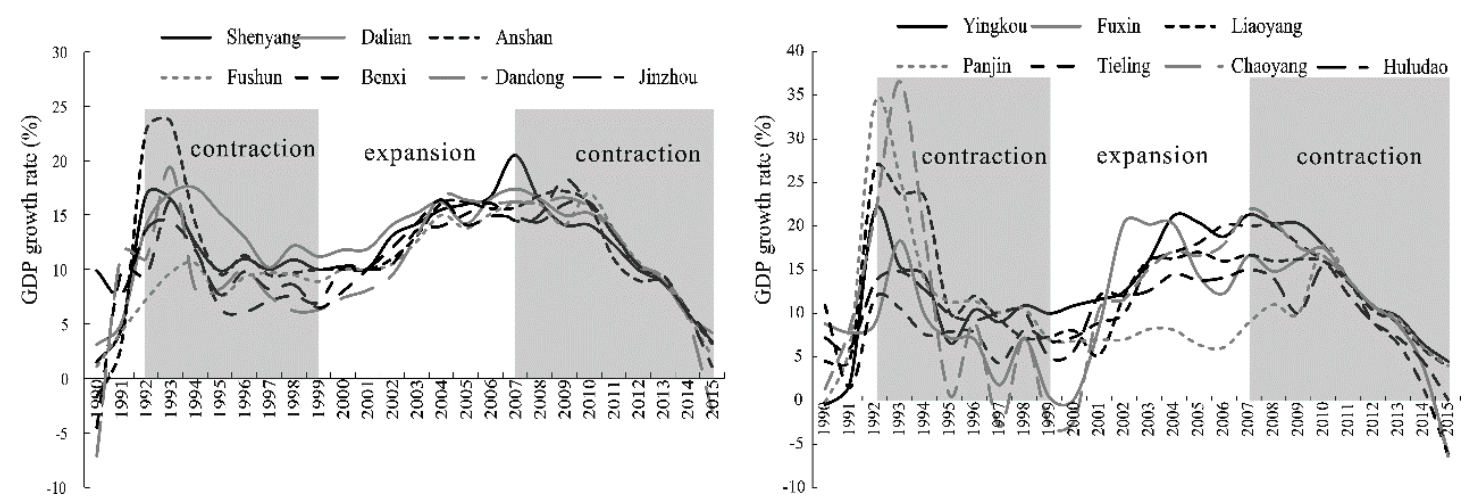

Figure 3. Urban GDP growth rates of different cities in Liaoning Province (1990-2015).

Overall, the economic and industrial history of Liaoning Province-i.e., the emergence of heavy industries, fast industrial development, economic recession, and regional revitalization-shows an apparent path-dependence characteristic [33], which is typical and representative for studying how a local economy responds to and recovers from shocks from the perspective of regional economic resilience.

\section{Measuring Regional Economic Resilience of Liaoning Province}

\subsection{Measuring Resistance and Recoverability}

Based on the three-period division of the economic cycles of 14 cities in Liaoning Province explained in the previous section (Figures 2 and 3), we measured the regional economic resilience in this section. Martin and Sunley stress that resilience is a process that involves several elements: regional vulnerability to shocks, regional resistance to shocks, regional adaptability to shocks, and the extent of regional recovery and development after shock [11]. The vulnerability and adaptability are closely related to the resistance and recoverability, respectively. Regions with high vulnerability are more vulnerable to shocks, and their ability to resist shocks is low. The areas that can maintain development and adjust to shocks will show high recoverability characteristics in the subsequent 
recovery and development stages. Therefore, in this paper, resistance and recoverability are chosen to reflect regional economic resilience [6,8]. The paper calculates the regional economic resistance or recoverability during the periods of contraction (1992-1999, 2007-2015) or expansion (1999-2007) to display the abilities of regional economic resilience [8]. The expected change of GDP in region $i$ during a recession or recovery, i.e., the duration of $k$ periods, would be given as

$$
\left(\Delta R_{i}^{t+k}\right)^{\text {expexted }}=\sum_{j}^{n} R_{i j}{ }^{t} \cdot G_{n}{ }^{t+k}
$$

where $R_{i j}^{t}$ is the output value of industry $j$ in region $i$ at starting time $t$, the base year, and $G^{t+k}{ }_{n}$ is the rate of contraction or expansion of the national output. Then, the resistance and recoverability can be expressed as

$$
\begin{gathered}
\text { Resistance }=\frac{\left(\Delta R_{i}{ }^{\text {contraction }}\right)-\left(\Delta R_{i}^{\text {contraction }}\right)^{\text {expected }}}{\left|\left(\Delta R_{i}{ }^{\text {contraction }}\right)^{\text {expected }}\right|} \\
\text { Recoverability }=\frac{\left(\Delta R_{i}{ }^{\text {expansion }}\right)-\left(\Delta R_{i}{ }^{\text {expansion }}\right)^{\text {expected }}}{\left|\left(\Delta R_{i}{ }^{\text {expansion }}\right)^{\text {expected }}\right|}
\end{gathered}
$$

A resistance that is larger than 0 means that the impact of the shocks on the region is less than that on the national average level; a recoverability that is larger than 0 means that the ability of recovery in the region after the shocks is better than that on the national average level.

\subsection{Results of Regional Economic Resilience Measurements}

The resistance and recoverability of the cities in Liaoning Province, which is calculated based on Equations (2) and (3), are shown in Figure 4.

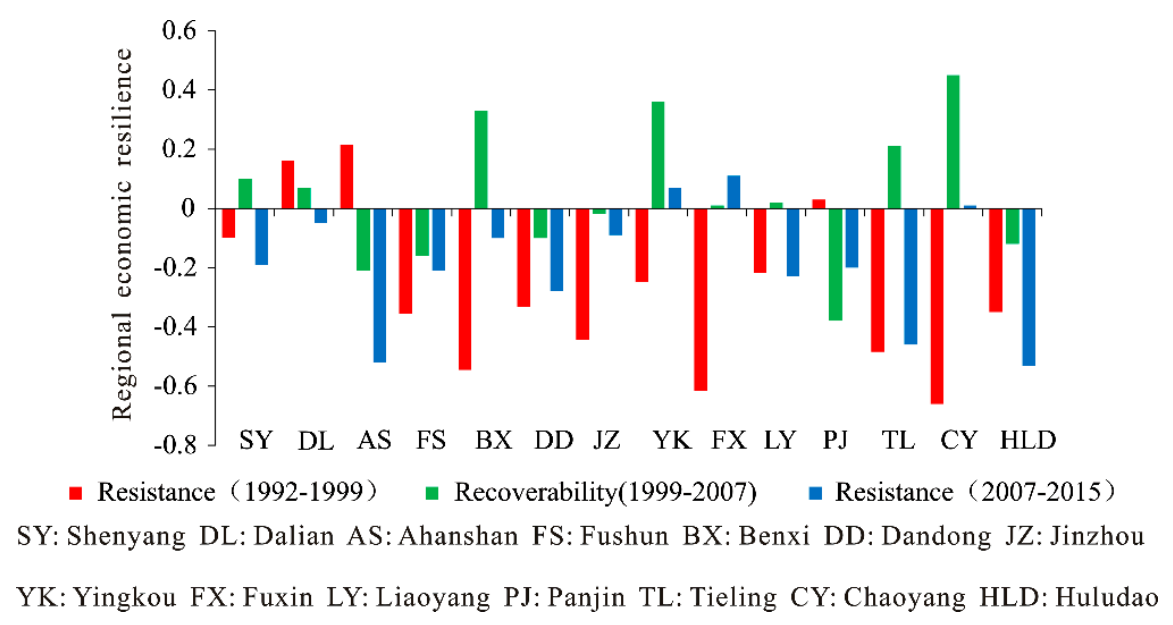

Figure 4. Resistance and recoverability of the cities in Liaoning Province (1992-2015).

As shown in Figure 4, the regional economic resilience levels of different cities in Liaoning were dynamically changing from 1992 to 2015, and the regional economic resilience levels were low. The resistance values of most cities were lower than 0 and these cities were quite vulnerable to external shocks from 1992 to 1999. This period occurred against the context of the Asian financial crisis. Meanwhile, old industrial bases in Northeast China, featuring traditional manufactory and heavy industries, were experiencing an economic recession [30]. These cities in Liaoning Province were suffering serious decays during this period and the resistance level of Liaoning Province to shock was low. Since 2003, when the central government of China initiated the "Revitalization of Old Industrial Bases in Northeast China" strategy, it had invested a great deal into equipment manufacturing and 
the raw materials industries and promoted state-owned enterprises reforms in Liaoning Province [30]. The economy of Liaoning old industrial base gradually recovered from 1999 to 2007. As shown in Figure 4 , there were 8 cities whose recoverability values were higher than 0 , which indicates their high economic recoverability; there were still six cities whose recoverability values remain less than 0, which implies their poor economic recoverability. From 2007 to 2015, most cities' resistance levels were less than 0 , with only Yingkou, Fuxin, and Chaoyang having resistance values higher than 0 , which means that the resistance of Liaoning was lower than the national average and very vulnerable to shocks.

\section{Determinants of Regional Economic Resilience in Liaoning Province}

\subsection{Determining Factors of Regional Economic Resilience}

Regional economic resilience is determined by a complex array of factors [8]. Regional resilience can be thought of as being determined by four main interacting economic subsystems: structural and business systems, labor market subsystems, financial subsystems, and governance subsystems $[2,4,6,11,34]$.

Industrial structure is considered to be a key factor affecting regional economic resilience. Different types of industry have different exposures to external competition [11], and some studies find that the regions dominated by manufacturing and construction industries show low economic resilience $[19,24]$. The secondary industry is severely restricted by resources and closely related to the market environment. When resources are exhausted or the external market demand is reduced, the regional economy will rapidly decline. The excessive development of secondary industry may limit the regional economic resilience. Liaoning Province, as a traditional old industrial base in China, has long relied on traditional industrial sectors for regional economic development. The proportion of secondary industry was high, being $50 \%, 48 \%, 50 \%$, and $46 \%$ in 1992, 1999, 2007, and 2015, respectively. In comparison, the regional tertiary industry is developing slowly. The particular structural rigidity of the industry may have a negative impact on the economic resilience of the old industrial bases. We adopted the proportions of the added values of the secondary industry to GDP to reflect the industrial structure of the 14 cities in Liaoning Province in this study, and it is expected to have a negative effect on regional economic resilience.

When impacts occur, regions with a good labor market can attract high-quality talent from other regions, and then promote the development of the region. Regions with a high unemployment rate will lose more of their high-quality labor force and may lose confidence in their future development, which limits the performance of regional economic systems to deal with shocks $[11,27]$. The old industrial bases have a large proportion of industrial sectors, and there are more employees engaged in industrial activities. When the old industrial bases were affected by the shock, it led to a large number of unemployed workers, and the regional labor market was therefore poorly developed. The level of regional unemployment rates will be a good measurement of the regional labor situation. The regions with low unemployment rate areas can create more jobs and the labor market is in a good status. Therefore, considering the characteristics of our study area, we selected the unemployment rate to reflect the labor market environment and the expected sign of the coefficient of unemployment rate on regional economic resilience is negative.

Financial environments are related to regional financing capacity. Excellent financial environments will not only attract a large amount of capital, but also attract high-end enterprises to settle in. They can provide financial support for the development of small and medium-sized enterprises, promote technology exchange and spillover, and enhance the adaptability of regional economic systems to the impact of shocks $[2,6,11,26]$. The actual use of foreign direct investment can reflect the financial environment and openness of the region. Generally, a region with a good financial environment can attract more foreign investment and promote knowledge spillovers between domestic and foreign companies. When a shock occurs, the company can adapt to changes in the environment and maintain 
the sustainable development of the regional economy $[6,26,35]$. Therefore, in this paper, we set the rate of FDI to GDP to reflect the financial environment and the expected sign of the coefficient of FDI on regional economic resilience should be positive.

The development of a regional economy cannot be separated from the government's policies. The governance arrangement can guide industrial development after the shock to resist impacts and restore developments. However, the factors of government systems have been often ignored in academics $[19,28]$, which may ignore the key role of government arrangements in regional responses to shocks. Positive regional support policies can support the development of enterprises, attract high-quality talent and promote technological innovation to respond positively to the impact of shocks $[25,27]$. Public finance expenditure is an important aspect of government arrangement, and it can be divided into productive expenditure and nonproductive expenditure according to its economic nature, which is used to promote regional economic development. The Liaoning old industrial base has long been affected by China's planned economy regime and thus its influence still exists currently. Its economic development is greatly influenced by government policies, which means that while good government arrangements will promote the long-term stable development of the regional economy, bad ones will lead to the opposite outcomes. Therefore, the paper selected the public finance expenditure per $10^{4}$ people to reflect the degree of government regulation of regional response to shocks. The expected sign of the coefficient of public finance expenditure on regional economic resilience should be positive.

There is a consensus among many studies that the innovation ability is an important factor for regional economic systems to deal with the impacts of disturbance $[4,6,25]$. The regional innovation level is a significant aspect of regional competitiveness, and it is also the foundation of regional long-term development. When the external environment changes, regions with high innovation levels have strong adaptability and can quickly recover or achieve path breakthroughs [2,23]. This paper selected the proportion of employees in scientific research and technical services to the total population to reflect the regional innovation ability, and the expected sign of the coefficient of innovation ability on regional economic resilience should be positive.

The diversity of the economic structure is another important factor that influences the regional economic resilience. It is generally believed that diversified economic structures can disperse the impacts of shocks and act as a "Shock Absorber" [3,4] so that the regions with a high diversity regional economic structure are less affected by shocks or are more likely to recover from shocks. However, regions with high economic specialization are highly sensitive to shocks [34,35]. These areas can enter locked states easily because of the high degrees of correlation, which leads to a weaker ability to evolve to new path. When the specialization industry is affected by the impact, the industry is seriously affected, which limits the resistance and recovery of the region to shocks and can easily cause the economy to enter a long-term recession track $[4,34,35]$. The Liaoning old industrial base has long relied on heavy industry. There are close interdepartmental links and the degree of economic structure specialization is quite high, which may limit the regional economic flexibility. When faced with the impact of China's economic development pattern change or the decline in demand for industrial products, regional economies are more likely to enter a recession trajectory. Therefore, we choose the Herfindahl-Hirschman index to measure the degree of diversity of economic structure, which is based on the number of employed people in different sectors. It is noteworthy that the higher the index, the lower the diversity. The expected sign of the coefficient of diversity of economic structure on regional economic resilience should be negative. The differences in economic resilience between regions may be related to the level of regional economic development [36,37]; therefore, the level of regional economic development is chosen as a control variable. The economic development level is based on the GDP per $10^{4}$ people.

Based on the literature review, data availability and regional characteristics, this study intends to explore the determinants of regional economic resilience in 14 cities of Liaoning Province using the following aspects: industrial structure, local labor market, financial environment, governance 
arrangement, innovation ability, diversity degree of the economic structure, and economic development level. We mainly focus on the periods of 1992-1999, 1999-2007, and 2007-2015, and the explanatory variables are calculated at the beginning of each subperiod [25,35]. Table 1 shows the detailed information for each variable:

Table 1. Description of variables.

\begin{tabular}{|c|c|c|c|c|}
\hline Variable & Description & Min & Max & Mean \\
\hline $\begin{array}{l}\text { Regional economic } \\
\text { resilience }\end{array}$ & Resistance and recoverability index & -0.6547 & 0.4531 & -0.1441 \\
\hline $\begin{array}{l}\text { Economic development } \\
\text { level (GDP) }\end{array}$ & $\begin{array}{l}\text { Gross domestic product/city population } \\
\text { (Log of the number) }\end{array}$ & 7.3165 & 10.8519 & 9.0248 \\
\hline $\begin{array}{l}\text { Governance arrangement } \\
\text { (GOV) }\end{array}$ & $\begin{array}{l}\text { Public finance expenditure/city population } \\
\text { (Log of the number) }\end{array}$ & 5.2652 & 8.6927 & 6.7745 \\
\hline $\begin{array}{l}\text { Financial environment } \\
\text { (FDI) }\end{array}$ & $\begin{array}{l}\text { Amount of foreign direct investment actually } \\
\text { utilized/GDP (Ratio) }\end{array}$ & 0.0002 & 0.1180 & 0.0271 \\
\hline Innovation ability (INO) & $\begin{array}{l}\text { Employment in scientific research and } \\
\text { technical services/city population (Ratio) }\end{array}$ & 0.0006 & 0.0131 & 0.0020 \\
\hline Labor market (UMP) & Unemployment rate (Ratio) & 0.0200 & 0.0850 & 0.0374 \\
\hline Industrial structure (IND) & Proportion of secondary industry (Ratio) & 0.2980 & 0.7151 & 0.4879 \\
\hline Economic diversity (HHI) & Herfindahl-Hirschman index & 0.1053 & 0.4129 & 0.2302 \\
\hline
\end{tabular}

The panel data are compiled from various source such as the China City Statistical Yearbook (National Bureau of Statistics, 1991-2016) and the Liaoning Statistical Yearbook (Liaoning Bureau of Statistics, 1991-2016).

\subsection{Analysis Model of Determinants of Regional Economic Resilience}

\subsubsection{Spatial Autocorrelation Moran Index}

The regional economic resilience between different cities in Liaoning Province may have spatial correlation characteristics because the spatial units are not independent of each other. The interrelationship between cities may affect the regional economic resilience levels of surrounding cities. Therefore, it is necessary to test the spatial correlation of regional economic resilience. Spatial autocorrelation is used to check whether there is spatial dependence between adjacent regions. If there is a spatial correlation, the dependence of spatial unit attributes should be considered in the regression analysis, and the regression analysis is performed by means of a spatial econometric model. Spatial autocorrelation is generally measured by the global Moran index

$$
\text { Moran's } I=\frac{\sum_{i=1}^{n} \sum_{j=1}^{n} W_{i j}\left(Z_{i}-\bar{Z}\right)\left(Z_{j}-\bar{Z}\right)}{S^{2} \sum_{i=1}^{n} \sum_{j=1}^{n} W_{i j}}, S^{2}=\frac{1}{n} \sum_{i=1}^{n}\left(Z_{i}-\bar{Z}\right), \bar{Z}=\frac{1}{n} \sum_{i=1}^{n} Z_{i}
$$

$S^{2}$ represents the variance; $Z$ represents the mean, $Z_{i}$ represents the observed value of the city $i ; n$ represents the number of research objects; and $W_{i j}$ is the spatial weight matrix. This paper uses the near-space weighted matrix, that is, the weight between adjacent areas is 1 , and the weight between non-adjacent areas is 0 . If Moran's $I>0$, then it indicates a positive spatial autocorrelation; if Moran's $I<0$, then it indicates a negative spatial autocorrelation; if Moran's $I=0$, then it indicates no spatial autocorrelation.

\subsubsection{Spatial Econometric Model}

The spatial econometric model considers the interaction between neighboring regions when the subjects are not independent. The most commonly used spatial econometric models are the spatial 
lag model (SLM) and the spatial error model (SEM) [38], which can be expressed as Formulas 5 and 6 , respectively

$$
y_{i t}=\rho W y_{i t}+\beta X_{i t}+\varepsilon_{i t}
$$

where $y_{i t}$ is the dependent variable matrix of region $i$ in the $t$ period; $X_{i t}$ is the independent variable matrix of region $i$ in the $t$ period; and $W_{i j}$ is the spatial weight matrix. This paper uses the near-space weighted matrix as mentioned in Section 4.2.1. $\beta$ reflects the parameter values of variable $X_{i t} . \rho$ is the spatial autoregressive coefficient, and $\rho$ reflects the influence of the adjacent areas on the area $i . \varepsilon$ is the residual value. The SLM mainly discusses whether the dependent variable of region $i$ is affected by the spillover effect of its neighboring areas.

$$
y_{i t}=\beta X_{i t}+\mu_{i t} \quad \mu_{i t}=\lambda W \mu_{i t}+\varepsilon_{i t}
$$

$\mu_{i t}$ and $\varepsilon_{i t}$ are random disturbance term, and $\lambda$ is the spatial error autocorrelation coefficient, and $\lambda$ reflects the influence of the adjacent regions' error impacts on area $i$. The spatial dependence of the spatial error model exists in the error term, which measures the adjacent region's error impact on dependent variable.

The dependent variables in this paper are the resistance index during the recession period, and the recoverability index during the expansion period.

\subsection{Estimation Results}

This part shows the results of the spatial correlation of the regional economic resilience in Liaoning Province in 1992-1999, 1999-2007, and 2007-2015. As shown in Table 2, there was a significant spatial autocorrelation of the resistance in 1992-1999 and the recoverability in 1999-2007, which means that it is necessary to consider the spatial dependence relationship of regional economic resilience when analyzing the determinants of regional economic resilience in 1992-2015. The spatial econometric model can reveal the dependence of regional economic resilience.

Table 2. Global Moran's I of regional economic resilience.

\begin{tabular}{cccc}
\hline & Resistance 1992-1999 & Recoverability 1999-2007 & Resistance 2007-2015 \\
\hline Moran's $I$ & $0.28^{* *}$ & $-0.27^{*}$ & -0.11 \\
$p$ value & 0.02 & 0.09 & 0.45 \\
\hline \multicolumn{4}{c}{${ }^{* * *} p<0.01 ;{ }^{* *} p<0.05 ;{ }^{*} p<0.1}$.
\end{tabular}

This paper used the Hausman test to decide if the model fit (a fixed effect model or a random effect model). The $t$ statistic value is 38.664 and the $p$ value is 0.001 for the results of the Hausman test, which refused to select the zero hypothesis of random effect model. Therefore, we chose the fixed effect spatial econometric model as the regression model using panel data, and this panel data model contains changes in 8 variables in 14 cities over three cross-sections. At the same time, the paper constructed a cross-section data model, and measured the regression results of the influencing factors in three time periods respectively, and then we compared with the regression results of the spatial panel data model to reflect the advantages of the panel data model. Table 3 displays the regression results. The second to fourth columns in Table 3 are the panel data model regression results, and the last three columns are the cross-section data model regression results. Among them, during the 2007-2015 period, the Moran index of regional economic resilience was not significant (see Table 2), so the last column in Table 3 is the regression result of the traditional OLS model. 
Table 3. Regression results of regional economic resilience influence factors.

\begin{tabular}{ccccccc}
\hline & OLS & SLM & SEM & SEM & SEM & OLS \\
& $\mathbf{1 9 9 2 - 2 0 1 5}$ & $\mathbf{1 9 9 2 - 2 0 1 5}$ & $\mathbf{1 9 9 2 - 2 0 1 5}$ & $\mathbf{1 9 9 2 - 1 9 9 9}$ & 1999-2007 $^{\text {2007-2015 }}$ \\
\hline Constant & 0.831 & & & $-5.704^{* * *}$ & $3.846^{* * *}$ & -2.776 \\
GDP & -0.101 & $-1.234^{* *}$ & $-1.340^{* * *}$ & $1.303^{* * *}$ & $-0.251^{* *}$ & -0.364 \\
GOV & 0.070 & $0.982^{* *}$ & $1.021^{* * *}$ & $-0.864^{* *}$ & $-0.261^{* *}$ & 0.882 \\
FDI & 2.162 & 1.938 & 2.033 & 0.175 & $5.614^{* * *}$ & -0.068 \\
INO & -7.281 & 33.325 & $67.854^{* * *}$ & -21.107 & -0.801 & -91.147 \\
UMP & -5.847 & -0.059 & -3.427 & 1.025 & $-7.732^{* *}$ & -7.325 \\
IND & -0.287 & -1.176 & $-2.638^{* * *}$ & $-1.509^{* *}$ & $-0.034^{* * *}$ & 0.524 \\
HHI & -1.000 & -1.503 & $-2.541^{* * *}$ & 1.689 & $1.559^{* * *}$ & -3.770 \\
$\rho / \lambda$ & & 0.105 & $-1.246^{* * *}$ & -0.416 & $-4.464^{* * *}$ & 0.359 \\
R $^{2}$ & 0.189 & 0.465 & 0.335 & 0.738 & 0.617 & 5.981 \\
LogL & 0.174 & 7.346 & 17.809 & 7.854 & 16.174 &
\end{tabular}

As shown in Table 3, the spatial econometric model, which considered the spatial dependence characteristics of regional economic resilience, fits better than the traditional regression. The goodness of fit $\left(\mathrm{R}^{2}\right)$ and the LogL value are higher than that of the traditional OLS model. At the same time, the regression results of the panel data model were better than the cross-section data model. Most of the variables in the cross-section data model cannot pass the significance test. The panel data model can take into account the time evolution and regional characteristics, and the regression results are more scientific. The higher LogL value indicates a better estimation effect of the model. The LogL value of the SEM (1992-2015) is the largest among the six models, and most of the independent variables are statistically significant. Therefore, we chose the SEM (1992-2015) as the final regression model for exploring the determinants of regional economic resilience in the 14 cities of Liaoning Province.

From Table 3 we can see that the regional public financial expenditure had a significantly positive impact on the regional economic resilience of Liaoning, and the estimated coefficient is 1.021. An increase of local public financial expenditure will enhance the resilience of regional economic systems to external shocks. The rate of employees in scientific research and technical services in the total population will also significantly and positively affect regional economic resilience. The increase in employees in scientific research and technical services can enhance the regional economic resilience in the face of shock. The FDI and unemployment rates did not pass the significance tests; however, the coefficients of the variables were positive and negative, respectively, which means that the FDI might be good for regional economic resilience, while the unemployment rate might have a negative impact on the regional economic resilience.

The industrial structure $(-2.638)$ had a significantly negative influence on the regional economic resilience. The characteristics of regional industrial structure is a key factor of regional economic resilience. The increase of the proportion of the secondary industry in Liaoning will function negatively to regional economy to cope with shocks. The Herfindahl-Hirschman index $(-2.541)$ significantly and negatively affects regional economic resilience. It means that the diversification of economic structure contributes to the improvement of regional economic resilience [3,4], in turn, the specialization of economic structure harms the ability of the regional economy to cope with shocks [35]. The economic development level also significantly and negatively affects regional economic resilience, which means that the improvement of the regional economic development level of Liaoning will restrict the regional economic resilience. The spatial error autocorrelation coefficient has a significantly negative influence on regional economic resilience, which indicates that the improvement of the economic resilience of the surrounding areas will lead to the decline of local regional economic resilience. 


\section{Discussion and Conclusions}

Regional economic resilience is considered to be important in explaining regional differences in response to economic recession [9]. In the field of regional studies, research on resilience is still in its infancy. Most studies analyze the regional economic resilience of Western countries from the national macrospatial scale, and there is a lack of research countries or regions in other context from a microspatial scale. Additionally, most of the existing studies only select one development stage to analyze regional economic resilience and ignore the spatial co-relationship between different regions, which is very likely to neglect the tempo-spatial features of regional economic resilience. This paper analyzed the regional economic resilience of the Liaoning old industrial base in China in terms of its resistance and recoverability from 1990 to 2015, by constructing a panel data spatial econometric model using panel data. Based on the characteristics of the research area, this paper explored the regional economic resilience determinants of the Liaoning old industrial base from eight aspects including the industrial structure, local labor market, financial environment, governance arrangement, innovation ability, the degree of diversity in economic structure, economic development level, and effects of surrounding areas.

Three key findings can be drawn from this research. First, the ability of most cities in Liaoning to resist shocks was low $(1992-1999,2007-2015)$ and their economic systems were very vulnerable; this is a typical case which manifest how old industrial bases react to shocks. Second, we found that the regional public finance expenditure, the number of employees in scientific research and technical services, and the diversity of economic structure had significantly positive effects on regional economic resilience in Liaoning. However, the industrial structure and economic development level were significantly negatively related to regional economic resilience in 14 cities in Liaoning Province. Third, regional economic resilience in 14 cities in Liaoning Province during the three periods also indicated a spatial autocorrelation. Interestingly, we have specific findings which show that the improvement of the economic resilience in the surrounding areas will lead to the decline of local regional economic resilience in Liaoning province. This may be related to the siphon effect of regional economic resilience. The economic systems of regions with high regional economic resilience normally perform well in response to external shocks, which can attract the influx of different resources such as human capital, financial capital, and technologies from surrounding areas that are seriously affected by the shock. Through this, high regional economic resilience will limit the economic resilience of the surrounding regions. This indicates that in the process of regional development, Liaoning Province should strengthen the relationship with the surrounding regions. The regions with high economic resilience should play a leading role in feeding-back and supporting the development of regions with low economic resilience.

Overall, the findings above suggest that Liaoning old industrial base has a weak ability to cope with shocks and is vulnerable to external disruptions, which has led the region to enter the economic recession. Moreover, new challenge has emerged in the regional economy development of old industrial bases such as Liaoning province, against the context of Chinese government's great emphasis on the transition of economic development mode from a labor- and resource-intensified economy to high-quality development in recent years [7]. Old industrial bases in China, which is struggling to recover from the last-round economic recession and whose current economy resilience might be too low to support such a smooth transition, need to enhance its regional economic resilience from various dimensions.

The first one possible strategy can be to attract more talents and increase capital investment to enhance regional innovation capability. The level of regional innovation is an important factor for enhancing regional economic resilience [6,23], and the regions with strong innovation capabilities can maintain economic development through structural and organizational adaptation in the face of shocks or use the shock to break the original path and create new development paths to restore economic development $[2,23]$. The improvement of innovation capability requires the input of human and financial capital, while in old industrial bases in China, such as Liaoning Province, has suffered serious 
population loss in recent years. Many high-quality talents have left [39], resulting in a shortage of human capital. At the same time, Liaoning Province's investment in science and technology research is insufficient. In 2015, Liaoning Province's R\&D expenditure accounted for 1.27\% of GDP, which is much lower than the national average (2.07\%). The innovation capacity of Liaoning Province is at a medium level in China, and Liaoning's innovation ability ranking has fallen from 8th in 2011 to 15th in 2015 [40]. Therefore, fully stimulating Liaoning's regional innovation potential can become a long-term driving force for enhancing Liaoning's regional economic resilience and realizing economic revitalization. Accelerating the industrial transformation and increasing the degree of economic diversity is the second possible strategy to increase the regional economic resilience. The economic structure of Liaoning Province has been featured by the excessive proportion of secondary industry. The proportion of secondary industry in Liaoning is higher than the national average. Meanwhile, the heavy industry's GDP has accounted for more than $70 \%$ of the total secondary industry for decades. The heavy industry sector is more vulnerable to market change [41]. This has led to a high degree of specialization in Liaoning, which has limited the degree of economic structure diversification and weakened the ability of the regional economy to cope with shocks. Last but not least, to improve local governance level can be another strategy for Liaoning Province to enhance regional economic resilience $[11,27,42]$. The Liaoning old industrial base has long been affected by China's planned economy regime and the central and local governments play an important role in guiding and promoting the development of the regional economy. The good place-based policy can provide an excellent software and hardware environment for the development of the enterprises, attracting high-quality talents and investments to stimulate the regional innovation potential $[2,8]$. Based on the regional economic development experiences in the past decades, we expect that top-down government arrangement will continue to play a key role for old industrial bases—-such as Liaoning Province- to respond to shocks, to enhance regional economic resilience, and to achieve economic revitalization.

Author Contributions: Conceptualization, L.L. and P.Z.; methodology, L.L.; formal analysis, L.L. and X.L.; resources, L.L. and P.Z.; writing-original draft preparation, L.L. and X.L.; writing-review and editing, L.L. and P.Z.

Funding: This work was supported by the National Natural Science Foundation of China $(41571152,41771179$, 41601124).

Conflicts of Interest: The authors declare no conflict of interest.

\section{References}

1. Simmie, J.; Martin, R. The economic resilience of regions: Towards an evolutionary approach. Camb. J. Reg. Econ. Soc. 2010, 3, 27-43. [CrossRef]

2. Eraydin, A. Attributes and characteristics of regional resilience: Defining and measuring the resilience of Turkish regions. Reg. Stud. 2016, 50, 600-614. [CrossRef]

3. Martin, R. Regional economic resilience, hysteresis and recessionary shocks. J. Econ. Geogr. 2011, 12, 1-32. [CrossRef]

4. Boschma, R. Towards an evolutionary perspective on regional resilience. Reg. Stud. 2015, 49, 733-751. [CrossRef]

5. Hu, X.; Hassink, R. Exploring adaptation and adaptability in uneven economic resilience: A tale of two Chinese mining regions. Camb. J. Reg. Econ. Soc. 2017, 10, 527-541. [CrossRef]

6. Tan, J.; Lo, K.; Qiu, F.; Liu, W.; Li, J.; Zhang, P. Regional Economic Resilience: Resistance and Recoverability of Resource-Based Cities during Economic Crises in Northeast China. Sustainability 2017, 9, 2136. [CrossRef]

7. Guan, H.; Liu, W.; Zhang, P.; Lo, K.; Li, J.; Li, L. Analyzing Industrial Structure Evolution of Old Industrial Cities Using Evolutionary Resilience Theory: A Case Study in Shenyang of China. Chin. Geogr. Sci. 2018, 28, 516-528. [CrossRef]

8. Martin, R.; Sunley, P.; Gardiner, B.; Tyler, P. How regions react to recessions: Resilience and the role of economic structure. Reg. Stud. 2016, 50, 561-585. [CrossRef] 
9. Reggiani, A.; De Graaff, T.; Nijkamp, P. Resilience: An evolutionary approach to spatial economic systems. Netw. Spat. Econ. 2002, 2, 211-229. [CrossRef]

10. Reggiani, A. Network resilience for transport security: Some methodological considerations. Transp. Policy 2013, 28, 63-68. [CrossRef]

11. Martin, R.; Sunley, P. On the notion of regional economic resilience: Conceptualization and explanation. J. Econ. Geogra. 2015, 15, 1-42. [CrossRef]

12. Holling, C. Resilience and stability of ecological systems. Ann. Rev. Ecol. Syst. 1973, 4, 1-23. [CrossRef]

13. Cerra, V.; Saxena, S.C. Growth dynamics: The myth of economic recovery. Am. Econ. Rev. 2008, 98, 439-457. [CrossRef]

14. Cerra, V.; Panizza, U.; Saxena, S.C. International evidence on recovery from recessions. Contemp. Econ. Policy 2013, 31, 424-439. [CrossRef]

15. Fingleton, B.; Garretsen, H.; Martin, R. Recessionary shocks and regional employment: Evidence on the resilience of UK regions. J. Reg. Sci. 2012, 52, 109-133. [CrossRef]

16. Doran, J.; Fingleton, B. Employment resilience in Europe and the 2008 economic crisis: Insights from micro-level data. Reg. Stud. 2016, 50, 644-656. [CrossRef]

17. Bristow, G. Resilient regions: Re-'place'ing regional competitiveness. Camb. J. Reg. Econ. Soc. 2010, 3, $153-167$. [CrossRef]

18. Modica, M.; Reggiani, A. Spatial economic resilience: Overview and perspectives. Netw. Spat. Econ. 2015, 15, 211-233. [CrossRef]

19. Davies, S. Regional resilience in the 2008-2010 downturn: Comparative evidence from European countries. Camb. J. Reg. Econ. Soc. 2011, 4, 369-382. [CrossRef]

20. Di, C. Recessions, recoveries and regional resilience: Evidence on Italy. Camb. J. Reg. Econ. Soc. 2015, 8, 273-291.

21. Cellini, R.; Torrisi, G. Regional resilience in Italy: A very long-run analysis. Reg. Stud. 2014, 48, 1779-1796. [CrossRef]

22. Brakman, S.; Garretsen, H.; Marrewijk, C. Regional resilience across Europe: On urbanisation and the initial impact of the Great Recession. Reg. Stud. 2015, 8, 225-240. [CrossRef]

23. Chapple, K.; Lester, T. The resilient regional labour market? The US case. Reg. Stud. 2010, 3, 85-104. [CrossRef]

24. Angulo, A.; Mur, J.; Trívez, F. Measuring resilience to economic shocks: An application to Spain. Ann. Reg. Sci. 2018, 60, 349-373. [CrossRef]

25. Giannakis, E.; Bruggeman, A. Determinants of regional resilience to economic crisis: A European perspective. Eur. Plan. Stud. 2017, 25, 1394-1415. [CrossRef]

26. Di, C. Testing and explaining economic resilience with an application to Italian regions. Pap. Reg. Sci. 2017, 96, 93-113.

27. Sagan, I.; Masik, G. Economic resilience. The case study of Pomorskie region. Raumforsch. Raumordn. 2014, 72, 153-164. [CrossRef]

28. Hassink, R. Regional resilience: A promising concept to explain differences in regional economic adaptability? Camb. J. Reg. Econ. Soc. 2010, 3, 45-58. [CrossRef]

29. Zhao, Q. Industrialization and urbanization and its paths' selection of Liaoning traditional industrial base. Econ. Geogr. 2005, 25, 329-332.

30. Zhang, P. Regional Development Report of Northeast China 2008; Science Press: Beijing, China, 2008.

31. Yang, D.; Zhao, Z. Investment explanation of stagnation of economic growth in Northeast China. Northeast Asia Forum. 2015, 24, 94-107, 128.

32. Bao, Z.; Li, X. Industrial Economy History of Liaoning Province; Social Sciences Academic Press: Beijing, China, 2014.

33. Jin, F.; Wang, J.; Yang, Y.; Ma, L.; Qi, Y. The paths and solutions of innovation development in Northeast China. Sci. Geogr. Sin. 2016, 36, 1285-1292.

34. Holm, J.; Østergaard, C. Regional employment growth, shocks and regional industrial resilience: A quantitative analysis of the Danish ICT sector. Reg. Stud. 2015, 49, 95-112. [CrossRef]

35. Mazzola, F.; Cascio, I.; Epifanio, R.; Giacomo, G. Territorial capital and growth over the Great Recession: A local analysis for Italy. Ann. Reg. Sci. 2018, 60, 411-441. [CrossRef] 
36. Petrakos, G.; Psycharis, Y. The spatial aspects of economic crisis in Greece. Camb. J. Reg. Econ. Soc. 2015, 9, 137-152. [CrossRef]

37. Palaskas, T.; Psycharis, Y.; Rovolis, A.; Stoforos, C. The asymmetrical impact of the economic crisis on unemployment and welfare in Greek urban economies. J. Econ. Geogr. 2015, 15, 973-1007. [CrossRef]

38. Anselin, L.; Florax, R. New Directions in Spatial Econometrics; Springer: Berlin, Germany, 1995.

39. Qi, W.; Liu, S.; Jin, F. Calculation and spatial evolution of population loss in Northeast China. Sci. Geogr. Sin. 2017, 37, 1795-1804.

40. Research group on development and strategy of science and technology of China. In Annual Report of Regional Innovation Capability of China 2015; Science Publishing House: Beijing, China, 2015.

41. Angulo, A.; Mur, J.; Trívez, F. Measure of the resilience to Spanish economic crisis: The role of specialization. Econ. Bus. Lett. 2014, 3, 263-275. [CrossRef]

42. Kakderi, C.; Tasopoulou, A. Regional economic resilience: The role of national and regional policies. Eur. Plan. Stud. 2017, 25, 1435-1453. [CrossRef]

(C) 2019 by the authors. Licensee MDPI, Basel, Switzerland. This article is an open access article distributed under the terms and conditions of the Creative Commons Attribution (CC BY) license (http://creativecommons.org/licenses/by/4.0/). 